\title{
VARIATION IN LINEAR DENSITY OF COMBED YARN DUE TO DYEING WITH REACTIVE DYE IN DIFFERENT SHADE PERCENTAGES
}

\author{
Abu Naser Md. Ahsanul Haque ${ }^{1}$, Md. Arafat Hossain², Md. Azharul Islam \\ ${ }^{1,2}$ Lecturer,Department of Textile Engineering, BGMEA University of Fashion \& Technology, Dhaka, Bangladesh, \\ ${ }^{3}$ Lecturer, Department of Textile Engineering, Daffodil International University, Dhaka, Bangladesh
}

\begin{abstract}
Though yarn dyeing is a significant part of wet processing, it still has some major obstacles. It loses its weight as well as strength due to wet treatment. A study on the changes of linear density in combed yarn due to different shade percentages of reactive dye has been conducted and the results are statistically analyzed. Remazol Red RR, Remazol Yellow RR and Remazol Blue RR were used for this experiment. The study reveals that dye shade percentage effects on the linear density negatively. Before $2.5 \%$ shade the yarn loss is greater and after 3.5\% shade linear density also decreases. $2.5 \%$ to $3.5 \%$ shade percentage can be taken as the range where loss of linear density is much less than the other percentages. The lowest loss percentage was found for $3 \%$ shade for every dyestuff among which Remazol Red RR was the least.
\end{abstract}

Key Words: Combed yarn, Loss percentage, Shade, Linear density.

\section{INTRODUCTION}

Linear density or count is widely used term in Textile industry when it comes to define fabric construction and yarn specification (weight per unit length or length per unit weight) those are made using staple fibers or filaments. The art of dyeing is a branch of applied chemistry in which a use of both physical and chemical principle is made in order to bring about a permanent union between the dyes and the textile material. Most usually we see the use of solid dyeing method for the coloration of fabrics that are used in textile industries. But yarn dyeing has a very exceptional identity. Though solid dyeing is much applied but the yarn dyeing has create the opportunity to make the fabric with different color where in solid dyeing several color effect cannot be imparted. Yarn dyeing is very much popular for the woven fabric especially for the check and stripe fabrics and used to produce stripe in knit fabric also.

Several researchers work with cotton yarn damage and count variations. Shaid A. et al. [1] investigated the shade variation, density variation and package dia variation. Package weight variation in yarn dyeing and focused on the various machine setting parameters of yarn dyeing machine. On another paper Karim S.K et al.[2] worked with melange yarn and suggested that it was found out that flock dyeing increases fibre damage when compared with grey fibres. The higher degree of damage of the dyed cotton fibres mixed with white ones has a negative effect on the quality of the melange cotton yarn.

Singh $\mathrm{G}$ et al. [3] concluded on his research that square root of linear density influences the dimensional parameters to variable degrees. This paper also observed that dimensional parameters also influences by stitch length, machine gauge and twist factor of yarn. William et al. [4] worked with the fibre length disturbance of yarn which causes the weight loss of yarn and reported that changes in a typical portion of fibre length distribution of fibre arrays of 50 samples of raw cotton and 65 of corresponding grey cloth and yarn are not of such a character as to affect the reliability of the estimates of staple length. Koo et al. [5] showed that the average elongation, fibre length and tenacity decreases after pre-treatment and this decrement of properties influences to loss the weight of yarn after dyeing. Behara et al. [6] investigated that after dyeing of spun cotton yarn the broken fibre amount was higher than that of cotton bale. It indicates that the strength at break of dyed fibre in yarn was weaker than cotton fibre in bale. This broken and weak fibre causes the weight reduction of yarn after dyeing. Moghassem A. R [7] suggested on his paper that fiber length by number and weight of grey cotton was longer than that of dyed cotton, while the amount of fiber nep and short fiber content of dyed cotton were more than those of grey cotton.

Dyed cotton yarns are used in Ready-made garments, Hosiery industries, Bag closing industry, Sports goods, Umbrella and carpet making, Book binding, Handloom textiles, Furnishing textiles, etc. But being so popular, a dyed yarn is less strong than a grey yarn. For the reason the speed of a weaving machine or a knitting machine are kept lower for the dyed yarn so that it does not breaks regularly. The paper tried to find out how yarn dyeing effects on the linear density of a yarn. The test is made on the cotton yarn by different shade percentages of three reactive dyes and summarized. 


\section{MATERIAL \& METHOD}

\subsection{Materials \& Sample Preparation}

For this process first $30 \mathrm{Ne}$ combed yarn was taken \& tested for some of its major properties. The results are furnished in table 1. After testing them 24 yarn samples of 500 meter length were taken. They all divided into three groups. Each group is for a single color with different shade percentages. Each one is folded in small size and knotted in two ends so that they do not become disheveled in wet treatment. Then they are individually scoured-bleached in single stage method with $5.0 \mathrm{~g} / \mathrm{L} \mathrm{NaOH}, 1.0 \mathrm{~g} / \mathrm{L}$ detergent, $5 \mathrm{~g} / \mathrm{L}$ Hydrogen per oxide, $1.0 \mathrm{~g} / \mathrm{L}$ acetic acid, $0.5 \mathrm{~g} / \mathrm{L}$ stabilizer and $1.0 \mathrm{~g} / \mathrm{L}$ sequestering agent. The process continued 60 minutes in $95^{\circ} \mathrm{c}$ and material- liquor ratio was 1:8. Then they are cold washed and dried in a sample dryer at $60^{\circ} \mathrm{c}$.

Table-1: Properties of 30Ne comb yarn

\begin{tabular}{|c|c|c|c|}
\hline Properties & Tests & Results & Average \\
\hline \multirow{3}{*}{$\begin{array}{l}\text { Twist factor } \\
t e x^{1 / 2} \times t p c\end{array}$} & Test 1 & 33.18 & \multirow{3}{*}{31.36} \\
\hline & Test 2 & 30.2 & \\
\hline & Test 3 & 30.7 & \\
\hline \multirow{3}{*}{$\begin{array}{l}\text { Tenacity } \\
\text { mN/Tex }\end{array}$} & Test 1 & 161.5 & \multirow{3}{*}{159.7} \\
\hline & Test 2 & 159.5 & \\
\hline & Test 3 & 158 & \\
\hline \multirow{3}{*}{$\begin{array}{l}\text { Elongation at } \\
\text { break } \%\end{array}$} & Test 1 & 4 & \multirow{3}{*}{4.07} \\
\hline & Test 2 & 4.2 & \\
\hline & Test 3 & 4 & \\
\hline \multirow{3}{*}{$\begin{array}{l}\text { Unevenness, } \\
\text { U\% }\end{array}$} & Test 1 & 9 & \multirow{3}{*}{9} \\
\hline & Test 2 & 9 & \\
\hline & Test 3 & 9 & \\
\hline \multirow{3}{*}{$\begin{array}{l}\text { Thick } \\
\text { Place/1000m }\end{array}$} & Test 1 & 22 & \multirow{3}{*}{25.67} \\
\hline & Test 2 & 30 & \\
\hline & Test 3 & 25 & \\
\hline \multirow{3}{*}{$\begin{array}{l}\text { Thin } \\
\text { Place/1000m }\end{array}$} & Test 1 & 0 & \multirow{3}{*}{0.33} \\
\hline & Test 2 & 0 & \\
\hline & Test 3 & 1 & \\
\hline \multirow{3}{*}{ Neps/1000m } & Test 1 & 51 & \multirow{3}{*}{53} \\
\hline & Test 2 & 63 & \\
\hline & Test 3 & 45 & \\
\hline
\end{tabular}

After the successful pretreatment they are weighted in a electric balance. Then Remazol red RR, Remazol blue RR \& Remazol yellow RR these 3 dyes are taken and 24 samples were dyed with 8 different shade percentages on the weight of the yarn. The selected shade percentages were $0.5 \%, 1.0 \%$, $1.5 \%, 2.0 \%, 2.5 \%, 3.0 \%, 3.5 \%$ and $4.0 \%$. And there are certainly different amount of dyeing auxiliaries for different shade percentages as practiced generally. For $0.5 \%$ shade, $6.0 \mathrm{~g} / \mathrm{L} \mathrm{NaOH} \& 30 \mathrm{~g} / \mathrm{L} \mathrm{NaCl}$, for $1.0 \%$ shade, $8.0 \mathrm{~g} / \mathrm{L} \mathrm{NaOH}$ $\& 40 \mathrm{~g} / \mathrm{L} \mathrm{NaCl}$, for $1.5 \%$ shade, $10.0 \mathrm{~g} / \mathrm{L} \mathrm{NaOH} \& 45 \mathrm{~g} / \mathrm{L}$ $\mathrm{NaCl}$, for $2.0 \%$ shade, $11.0 \mathrm{~g} / \mathrm{L} \mathrm{NaOH} \& 50 \mathrm{~g} / \mathrm{L} \mathrm{NaCl}$, for $2.5 \%$ shade, $12.0 \mathrm{~g} / \mathrm{L} \mathrm{NaOH} \& 55 \mathrm{~g} / \mathrm{L} \mathrm{NaCl}$, for $3.0 \%$ shade, $14.0 \mathrm{~g} / \mathrm{L} \mathrm{NaOH} \& 60 \mathrm{~g} / \mathrm{L} \mathrm{NaCl}$, for $3.5 \%$ shade, $14.0 \mathrm{~g} / \mathrm{L} \mathrm{NaOH} \& 65 \mathrm{~g} / \mathrm{L} \mathrm{NaCl}$, and for $4.0 \%$ shade, $15.0 \mathrm{~g} / \mathrm{L}$ $\mathrm{NaOH} \& 70 \mathrm{~g} / \mathrm{L} \mathrm{NaCl}$ is added for exhaustion \& fixation. Dyeing is done for 1 hour in $60^{\circ} \mathrm{c}$ with a $\mathrm{M}$ : $\mathrm{L}$ ratio of $1: 8$. The dyeing was done in a industry dyeing lab in a closed bath sample dyeing machine. After that the samples treated through a cold wash and a hot wash $\left(70^{\circ} \mathrm{c}\right)$ with $1.0 \mathrm{~g} / \mathrm{L}$ detergent and again a cold wash respectively. After that they are dried in a sample dryer at $60^{\circ} \mathrm{c}$. Then the above specimens are conditioned for 72 hours in a standard atmosphere of $27 \pm 2 \mathrm{c}$ and $65 \pm 2 \% \mathrm{RH}$.

\subsection{Sample Analysis Procedure}

The target is to determine how the linear density of a yarn behaves with different shade percentages of a dye. So the Loss\% of the linear density of a yarn due to dyeing can be calculated as-

\section{$\frac{\text { Inatial Weight }- \text { Weight After Dyeing }}{\text { Initial Weight }} \times 100$}

Values of loss\% for each dye for each shade percentages are noted and shown in the table 3 . After getting the values of the Loss\%, graphs has been made by plotting the Loss\% in yaxis and shade percentage in x-axis. The graphs (Figure 1, 2, $3 \& 4$ ) can show the relation between weight loss $\%$ of yarn with the increasing shade percentages of the dyes.

Table-2: Weight loss\% of $30 \mathrm{Ne}$ comb yarn after dyeing for different dyes at different shade\%

\begin{tabular}{|c|c|c|c|c|}
\hline Dyes & Shade\% & $\begin{array}{l}\text { Before } \\
\text { dyeing } \\
\text { weight } \\
(\mathrm{gm})\end{array}$ & $\begin{array}{l}\text { After } \\
\text { dyeing } \\
\text { weight } \\
(\mathrm{gm})\end{array}$ & Loss $\%$ \\
\hline \multirow{10}{*}{$\begin{array}{l}\text { Remazol } \\
\text { Red RR }\end{array}$} & 0.5 & 9.89 & 9.30 & $5.97 \%$ \\
\hline & 1.0 & 9.86 & 9.34 & $5.27 \%$ \\
\hline & 1.5 & 9.87 & 9.46 & $4.15 \%$ \\
\hline & 2.0 & 9.88 & 9.50 & $3.85 \%$ \\
\hline & 2.5 & 9.86 & 9.53 & $3.35 \%$ \\
\hline & 3.0 & 9.85 & 9.61 & $2.44 \%$ \\
\hline & 3.5 & 9.84 & 9.49 & $3.56 \%$ \\
\hline & 4.0 & 9.86 & 9.48 & $3.85 \%$ \\
\hline & 4.5 & 9.87 & 9.44 & $4.36 \%$ \\
\hline & 5.0 & 9.85 & 9.42 & $4.37 \%$ \\
\hline \multirow{10}{*}{$\begin{array}{l}\text { Remazol } \\
\text { Yellow } \\
\text { RR }\end{array}$} & 0.5 & 9.90 & 9.32 & $5.86 \%$ \\
\hline & 1.0 & 9.88 & 9.35 & $5.36 \%$ \\
\hline & 1.5 & 9.83 & 9.40 & $4.37 \%$ \\
\hline & 2.0 & 9.87 & 9.48 & $3.95 \%$ \\
\hline & 2.5 & 9.85 & 9.51 & $3.45 \%$ \\
\hline & 3.0 & 9.86 & 9.57 & $2.94 \%$ \\
\hline & 3.5 & 9.88 & 9.50 & $3.85 \%$ \\
\hline & 4.0 & 9.89 & 9.47 & $4.25 \%$ \\
\hline & 4.5 & 9.84 & 9.42 & $4.27 \%$ \\
\hline & 5.0 & 9.87 & 9.43 & $4.46 \%$ \\
\hline \multirow{10}{*}{$\begin{array}{l}\text { Remazol } \\
\text { Blue RR }\end{array}$} & 0.5 & 9.85 & 9.33 & $5.28 \%$ \\
\hline & 1.0 & 9.86 & 9.36 & $5.07 \%$ \\
\hline & 1.5 & 9.88 & 9.41 & $4.76 \%$ \\
\hline & 2.0 & 9.84 & 9.45 & $3.96 \%$ \\
\hline & 2.5 & 9.88 & 9.52 & $3.64 \%$ \\
\hline & 3.0 & 9.87 & 9.58 & $2.94 \%$ \\
\hline & 3.5 & 9.86 & 9.52 & $3.45 \%$ \\
\hline & 4.0 & 9.88 & 9.47 & $4.15 \%$ \\
\hline & 4.5 & 9.83 & 9.42 & $4.17 \%$ \\
\hline & 5.0 & 9.86 & 9.43 & $4.36 \%$ \\
\hline
\end{tabular}




\section{RESULT \& DISCUSSION}

Here we get almost very similar results for all the dyestuffs. They all started with a great fiber loss. Then the curves go down that means loss of linear density comes down with the increase of dye percentage. In compare with fabric dyeing, we see that fabric GSM increases after dyeing due to dye take up. But in case of yarn, strength is lost due to wastage of fiber and after increasing the dye shade percentage, the take up also increases. For that reason the yarn gains some weight and linear density increases.

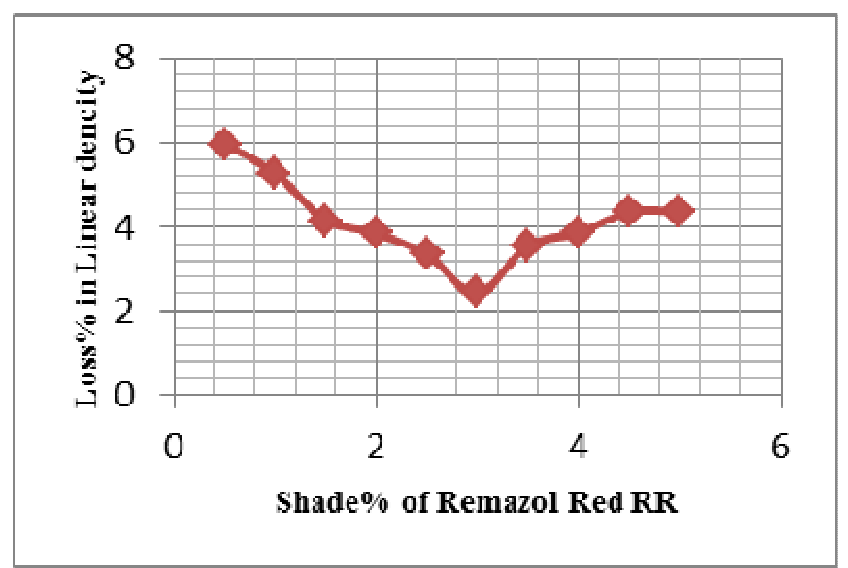

Figure 1: Effect of shade\% of Remazol Red RR on weight loss \% in linear density

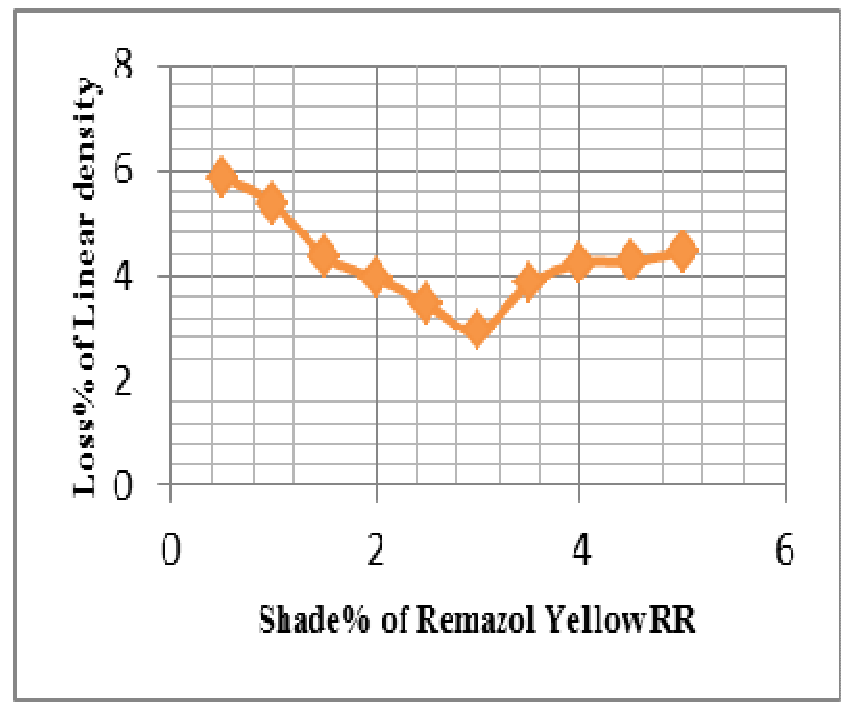

Figure 2: Effect of shade\% of Remazol Yellow RR on weight loss $\%$ in linear density

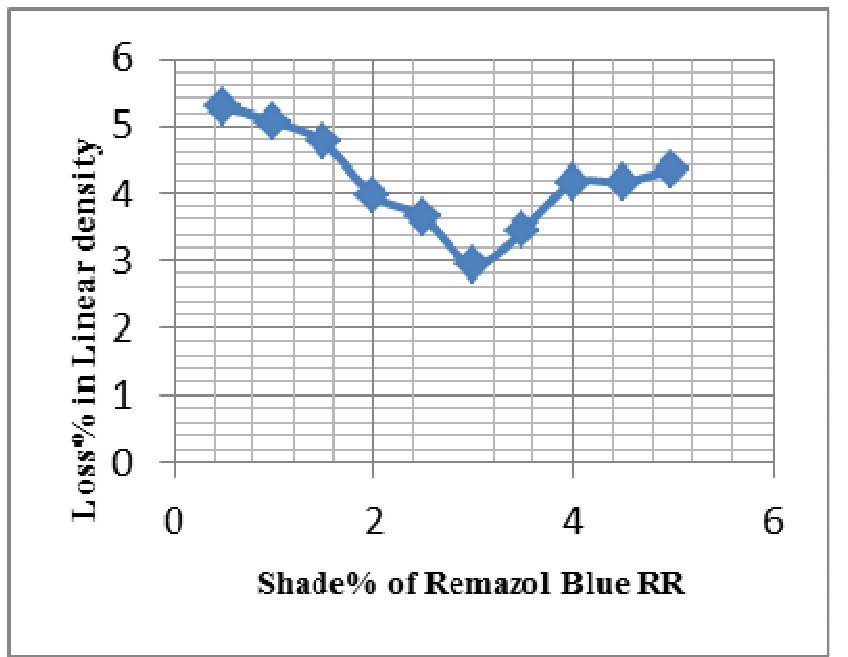

Figure 3: Effect of shade\% of Remazol Blue RR on weight loss $\%$ in linear density

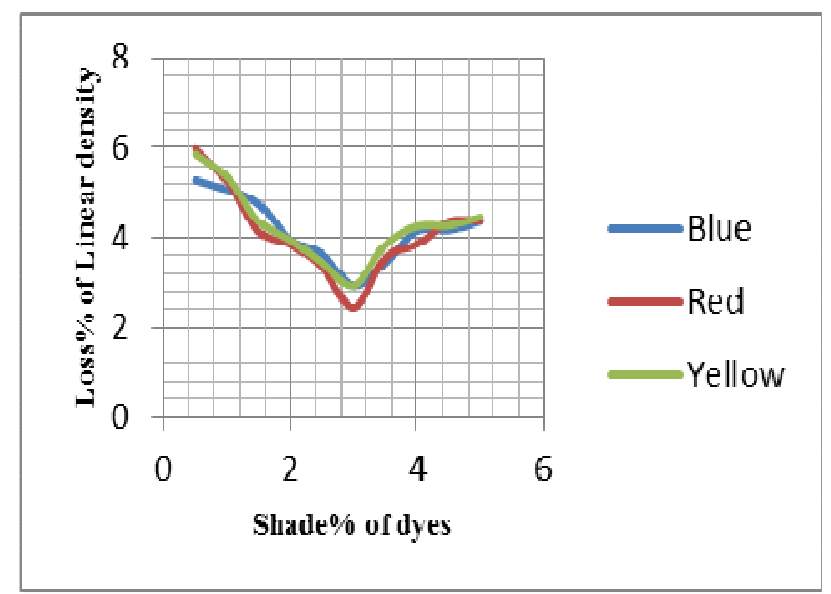

Figure 4: Comparison among Remazol Red RR, Yellow RR \& Blue RR against weight loss \% in linear density

From figure 1 , figure 2 , figure $3 \&$ table 2 , it is clear that in every case higher weight of yarn (Remazol Red $R R=9.61$ gm, Remazol Yellow RR=9.57 gm, Remazol Blue RR=9.58 gm) was observed at $3 \%$ shade after dyeing. It was also observed that up to $3 \%$ shade loss $\%$ of linear density decreases and after that loss $\%$ increases. In addition, it was also perceived that the ratio of loss $\%$ from $0.5 \%$ shade to $3 \%$ shade is higher than the ratio of loss $\%$ from $3 \%$ shade to $5 \%$ shade. Figure 4 shows the summary of all dyes and it confirms that minimum loss $\%$ of linear density is found for Remazol Red RR $(2.44 \%)$ at 3\% shade where at 3\% shade Remazol Yellow RR and Remazol Blue RR shows $2.94 \%$ loss.

Now the question is why there is such a point. For all the three dyeing $3 \%$ shade of dye gave the lower loss of yarn. And $2.5 \%$ and $3.5 \%$ shade $\%$ gave the value closer to the lowest. So we can identify the range $2.5 \%-3.5 \%$ as the area where yarn losses its linear density in a lower limit.

May be it is because, how much fiber have been lost are recovered in sense of weight by this range of shade\%. Before this range yarn cannot recover its loss of weight because it 
does not get sufficient amount of dyes. Moreover the loss gradually increases after this range in a lower rate. With the increase of dye shade\% the amount of salt and $\mathrm{NaOH}$ are also increases. So this lost must be because of the high amount of $\mathrm{NaOH}$, which can hydrolyze the cellulose at a high concentration.

\section{CONCLUSIONS}

Yarn dyeing is needed highly for the exceptional design perspective. If we can do the dyeing with less harm to the yarn surface, that will be better both for the weaving and knitting process. After the experiment we can come to the following conclusion-

1. Linear density of yarn must be lost due to dyeing.

2. Loss is greater before $2.5 \%$ of shade percentage.

3. Loss also increases slowly after $3.5 \%$ shade percentage.

4. So $2.5 \%-3.5 \%$ shade can said as safe zone for yarn.

5. Before or after the safe zone we should take extra care or can use related chemicals to keep the yarn more safe.

\section{ACKNOWLEDGEMENT}

The authors gratefully acknowledge the help \& support from Impress-Newtex Composite Textile Ltd, Gorai, Mirzapur, Tangail, Bangladesh.

\section{REFERENCES}

[1].Abu Shaid,Md. Abdus Shahid, Md. Abdur Rahman Bhuiyan, Md. Abdullahil Kafi, Shekh Md. Mamun Kabir, Md. Azijur Rahman, International Journal of Engineering \& Technology IJET-IJENS, Vol: 11 No:1 PP: 241-248.

[2].S. Karbalaie Karim, A. A. Gharehaghaji, H. Tavanaie, A Study of the Damage Caused to Dyed Cotton Fibres and its Effects on the Properties of Rotor- and Ring-Spun Melange Yarns, Fibres \& Textiles in Eastern Europe, July/September 2007, Vol.15, No. 3, PP:63-67.

[3].G. Singh, K Roy, R Varshney \& A Goyal, Dimensional parameters of single jersey cotton knitted fabrics, Indian Journal of Fibre \& Textile Research, Vol, 36, June 2011, PP: 111-116.

[4].Williams J.F., Vlases G. and Fielding H., 'The effect of manufacturing processes on the fibre length distribution and staple length of raw cotton used in grey yarn and grey cloth', Textile Research Journal, 1950, PP: 719-725

[5].Koo J. G., Park, J.W. and An S.K., 'Properties of specialty yarns based on raw and dyed cotton', Textile Research Journal, vol. 73, 2003, PP: 26-30.

[6].Berberi, P.G. 1991, 'Effect of lubrication on spinning properties of dyed cotton fibers', Text. Res. J, vol. 61, May, PP: 285-288.

[7].A.R. Moghassem, Study on the Dyed Cotton Fibers Damage in Spinning Processes and its Effect on the Cotton Mélange Yarn Properties, RJTA Vol. 12 No. 1 2008, PP: 7178.

\section{BIOGRAPHIES}

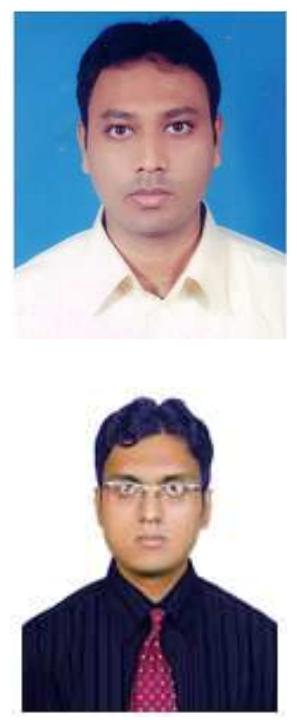

Abu Naser Md. Ahsanul Haque completed his graduation from College of Textile Technology, University of Dhaka. His area of interest textile wet process. He has 4+ years of teaching experience.

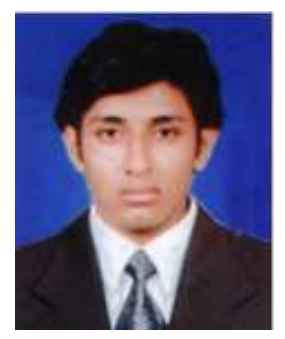

Md. Arafat Hossain finished his graduation from Ahsanullah University of Science \& Technology. He has more than 4 years of teaching experience and previously worked as quality inspection \& audit officer in a multinational company.

Md. Azharul Islam completed his graduation from College of Textile Technology, University of Dhaka. His interest area in textile is fabric manufacturing technology. He has teaching experience over 4 years and currently working at Daffodil International University. 